\title{
An empirical study on measuring the effects of different factors on environmental ethics
}

\author{
Akram Mansouri $^{\mathrm{a}}$ and Ahmad Ahmadkhani ${ }^{\mathrm{b}}$
}

${ }^{a}$ Department of Religious Mysticism, Islamic Azad University, Zanjan Branch, Zanjan, Iran

${ }^{b}$ Sama Technical Vocational Training College, Islamic Azad University, Zanjan Branch, Zanjan, Iran

\begin{tabular}{|c|c|}
\hline ART ICLE I NFO & A B S T R A C T \\
\hline $\begin{array}{l}\text { Article history: } \\
\text { Received January 8, } 2012 \\
\text { Received in Revised form } \\
\text { April, 25, } 2012 \\
\text { Accepted } 1 \text { May } 2012 \\
\text { Available online } \\
\text { May } 3 \text { 2012 } \\
\text { Keywords: } \\
\text { Environment } \\
\text { Ethical environment } \\
\text { Culture }\end{array}$ & $\begin{array}{l}\text { Environment plays an important role on human being's present and future life. A clean and } \\
\text { healthy environment can contribute to all societies and help people reach prosperity and } \\
\text { success. Environmental ethics is the investigation of ethical relationships between human } \\
\text { beings and the natural environment, which includes the nonhuman creatures. In environmental } \\
\text { ethics, we normally look for the proper way to understand the relationship between humans and } \\
\text { the natural environment, detect the values emerging from the relationship, the principles and } \\
\text { rules of action and characteristics do those goods and values justify. In this study, we } \\
\text { investigate the effects of different variables including responsibility, social ethics, education } \\
\text { and traditional and religious values on environment and environmental behavior. The study is } \\
\text { executed in two regions of city of Zanjan, Iran based on a questionnaire consists of } 400 \text { people. } \\
\text { A Pearson correlation test is performed among different components and the results indicated } \\
\text { that all mentioned variables influence environmental ethics, significantly. However, } \\
\text { normalization variable does not have any impact on environment. The preliminary results } \\
\text { indicate culture plays an important role on people's behavior in society. }\end{array}$ \\
\hline
\end{tabular}

\section{Introduction}

Environment is an important component of human life created purposely to help all existing creatures live in this planet. Unfortunately, we have seen some damaging changes on environment such as pollutions created by industries, which have increased green gas effects. As a result, we see some irreversible damaging effects such as an increase on weather temperature. If such circumstances continue, within 30 years, the coldest days during the wintertime would be warmer than present summer times. Therefore, there will be a big shortage of clean water for drinking, food and many people die of poverty. This event is not desirable for many since it could impact human life and reduces the populations, substantially.

These days, many governmental agencies try to reach some agreements on reducing green gas effects but they normally do not actively stay faithful with what they promise in their meetings. Human life

* Corresponding author.

E-mail addresses: adahmadkhani@gmail.com (A. Ahmad Khani) 
style has been one of the main factors for blaming global warming. People use cow meat as part of their food and this creates significant amount of $\mathrm{Co}_{2}$, they use non-recyclable materials, which contributes to global warming, many industries use fissile based fuels, which substantially add to whether temperature. Human nature seems to have sort of selfish attitude for paying less attention to environment. In fact, during the past few years, there has been a growing concern that a significant portion of deterioration of the environment is not so much an environmental problem as a human one, and the actual problem goes back to distorted and unbalanced perception of existence.

Anderberg (1998) studied industrial metabolism and the linkages between economics, ethics and the environment. He explained that there had been an increasing emphasis on the international and global environmental problems and the materials flow perspective is a major breakthrough. Waste minimization, recycling, life-cycle analysis and environmental auditing have become major problem in the world. Anderberg investigated the relative importance of the consumer and his/her attitudes and actions, and the relationship between trade and environment.

Ethical behavior has been one of the most important issues among researchers and it is globally accepted that ethical people may harm less on environment. Fox and Ward (2008) performed a qualitative study on motivations of vegetarians. They used discussions on the board on a website, gathered replies to questions from 33 participants, and conducted follow-up e-mail interviews with 18 them. Respondents were predominantly from the US, Canada and the UK and 70\% were females, and ages ranged from 14 to 53, with a median of 26 years. While this research found that health and the ethical treatment of animals were the primary motivators for participants' vegetarianism, participants reported a range of commitments to environmental concerns. Brans (2002) explained that many realworld problems can be faced by qualitative as well as quantitative issues, or by measurements and by perceptions, etc. and compared the management of Natural Real World issues and the management of Human Real World issues. He explained that despite the fact that there are similarities among various issues, there are some differences as well. Any decision-making for Human processes needs to consider three concepts including the rational, the subjective and the ethical one. Brans explained that some mathematical techniques could be used to provide well-balanced solutions between Rationality, Subjectivity and Ethics, where both the Mind of the Decision-maker and the "Ethical Conscience" of Mankind can be considered.

Macbeth (2005) discussed ethical issues on tourism industries. Wareham and Elefsiniotis (1996) discussed some missing issues in environmental ethics in engineering education. They reviewed the way in which engineers interact with the environment and argued that future engineering should be part of a paradigm shift in which engineers were seen as responsible stewards rather than negligent trustees of the environment. They also argued that training in environmental ethics should be considered as a fundamental skill taught in all engineering programs. Schug (2008) investigated on the institutional implications of environmental ethics for fishery management in the US exclusive economic zone. He argued that the capacity of regional fishery management councils to be adequately responsive to different ethical values and reported that legislative efforts to broaden council membership were unsuccessful and there must be a pressure for institutional reform to increase with the adoption of an ecosystem approach to fishery management.

According to Sandler (2012) environmental ethics is the investigation of ethical relationships between human beings and the natural environment, which includes the nonhuman creatures. In environmental ethics, we normally look for the proper way to understand the relationship between humans and the natural environment, detect the values emerging from the relationship, the principles and rules of action and characteristics do those goods and values justify. We also look for principles and regulations involved in humans interaction with and treat the natural environment.

Islam, as a religion has its own ethical rules and regulations for taking care of environmental issues. Kamla et al.(2006) discussed Islam rules on accounting and explained Islamic principles and notion 
of accounting for environment. Al-Khatib et al. (2005) discussed inter-country differences of consumer ethics in Arab countries. Ebadollahi Chanzanagh and Akbarnejad (2011) discussed the meaning and dimensions of Islamic work ethic among different Iranian societies.

\section{The proposed method}

The proposed study of this paper considers the following five hypotheses,

1. There is a relationship between feeling responsible in society and taking care of environment.

2. There is a relationship between social ethics in society and taking care of environment.

3. There is a relationship between normalization implemented on behalf of organizations and taking care of environment.

4. There is a relationship between education and awareness in society and taking care of environment.

5. There is a relationship between traditional and religious values from society and taking care of environment.

The proposed study of this paper designs a questionnaire and distributes among 400 people who were randomly selected from two regions of a city of Zanjan, which is located in west part of Iran. The sample size was calculated based on Kokran sampling technique and they are distributed in two regions, equally.

\section{The results}

We have used Pearson correlation test where the level of significance is set to 95\% and P-value is 0.000. The null hypothesis for all five hypotheses is that there is no relationship between the variable of taking care of environment. Table 1 shows details of our test results for the first hypothesis.

Table 1

Pearson correlation test results between being responsible and taking care of environment

\begin{tabular}{llll}
\hline Variable & Correlation & P-value & Result \\
\hline Being responsible & 0.21 & 0.000 & Confirmed \\
\hline
\end{tabular}

Table 1 shows the results of the responses for the first question of the survey. The correlation ration of 0.21 indicates that there is a positive relationship between these two components. Fig. 1 shows the frequency of the responses on this variable. As we can observe, 180 out of 200 people strongly believed that having a good sense of responsibility against environment could significantly impact for taking care of the environment.

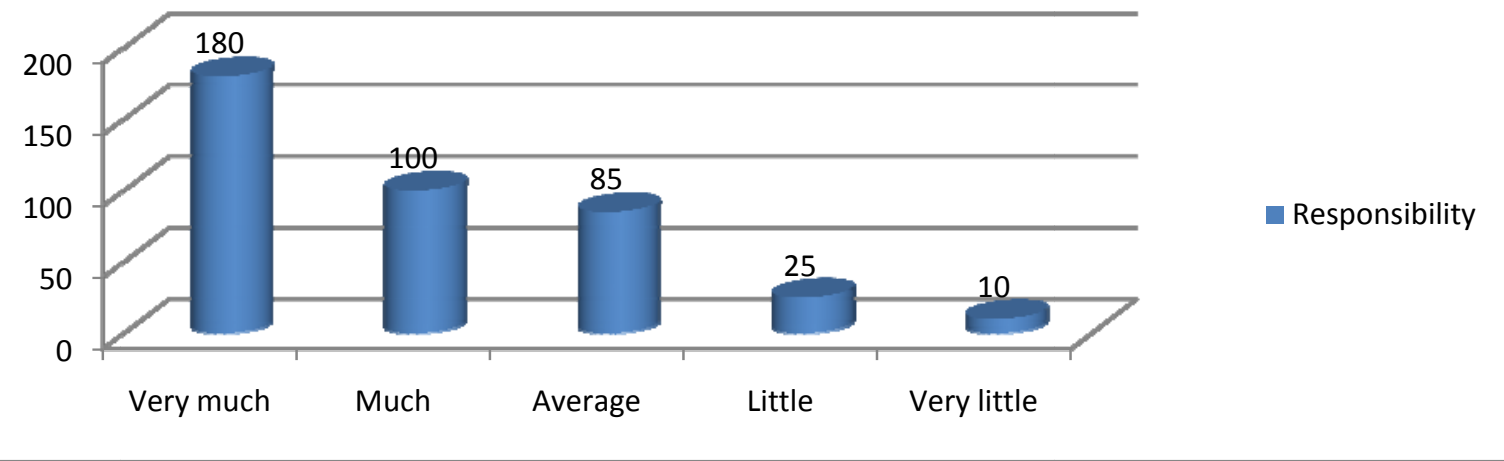

Fig. 1. The frequency of responses on the relevant importance of responsibility on environment 
The second hypothesis investigates the relationship between social ethics and environment. Table 2 shows details of our test results for the second hypothesis.

Table 2

Pearson correlation test results between social ethics and taking care of environment

\begin{tabular}{llll}
\hline Variable & Correlation & P-value & Result \\
\hline Social ethics & 0.39 & 0.000 & Confirmed
\end{tabular}

Table 2 shows the results of the responses for the second question of the survey. The correlation ratio of 0.39 indicates that there is a positive relationship between these two components. Fig. 2 shows the frequency of the responses on this variable. As we can observe, 160 out of 200 people strongly believed that having a good sense of responsibility against environment could substantially influence on the environment.

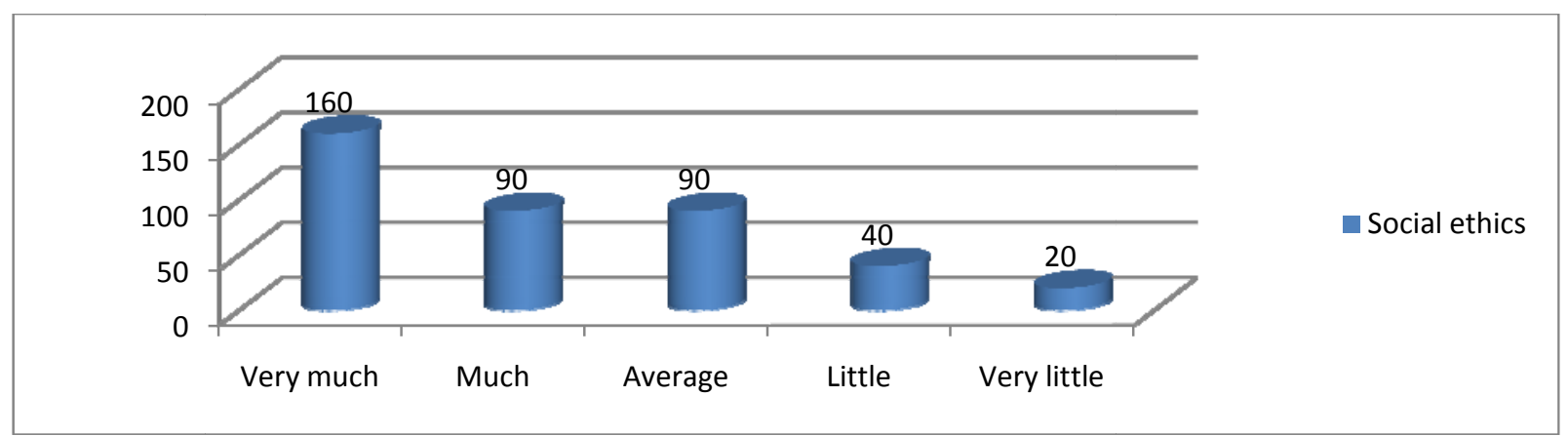

Fig. 2. The frequency of responses on the relevant importance of social ethics on environment

The third hypothesis studies the relationship between normalization and environment. Table 3 shows details of our test results for the third hypothesis.

Table 3

Pearson correlation test results between normalization effects from different organizations and taking care of environment

\begin{tabular}{llll}
\hline Variable & Correlation & P-value & Result \\
\hline Normalization & 0.21 & 0.059 & Confirmed \\
\hline
\end{tabular}

Table 3 shows the results of the responses for the third question of the survey. The P-value indicates that there is no meaningful relationship between the normalization effects and environmental issues. Fig. 3 shows the frequency of the responses on this variable. As we can observe, most of the people believed that normalization has no impact on taking care of the environment. In other words, governmental regulation does not play an important role on reducing any damage on environment.

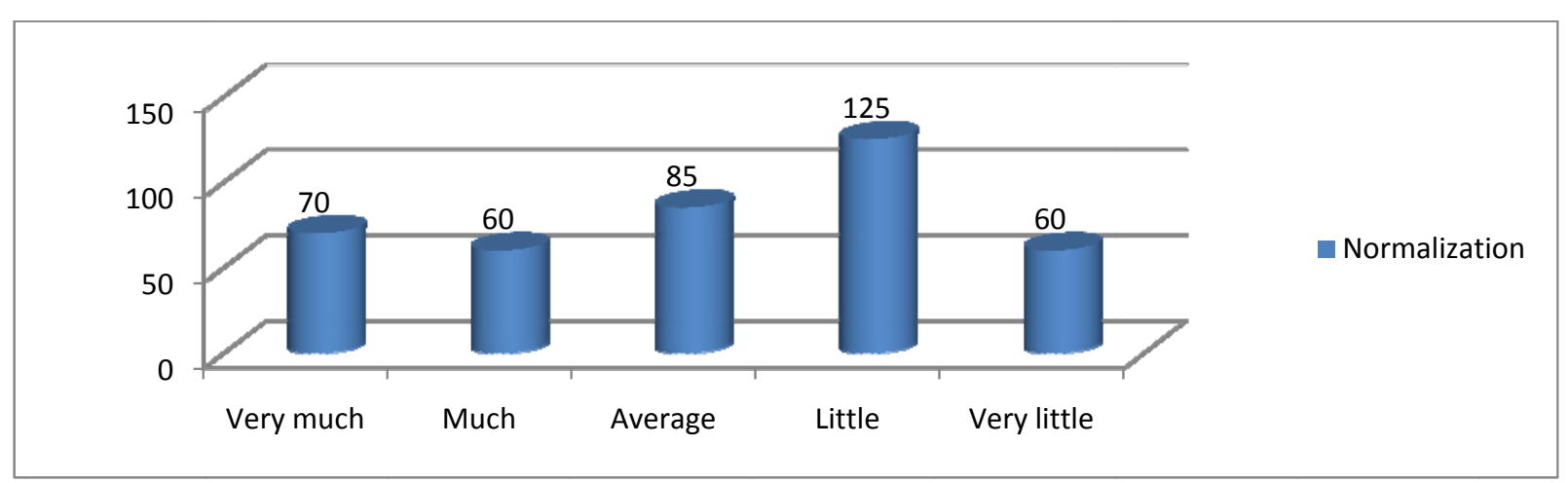

Fig. 3. The frequency of responses on the relevant importance of normalization on environment 
Next hypothesis studies the relationship between education and environment. Table 4 shows details of our test results of this hypothesis.

Table 4

Pearson correlation test results between educational effects on taking care of environment

Variable $\quad$ Correlation $\quad$ P-value $\quad$ Result

\begin{tabular}{llll}
\hline Education & 0.13 & 0.000 & Confirmed
\end{tabular}

Table 4 demonstrates the results of the responses for the fourth question of the survey. The P-value indicates that there is a meaningful relationship between educations effects and environmental issues and Pearson correlation indicates the relationship is indeed positive. Fig. 4 shows the frequency of the responses on this variable.

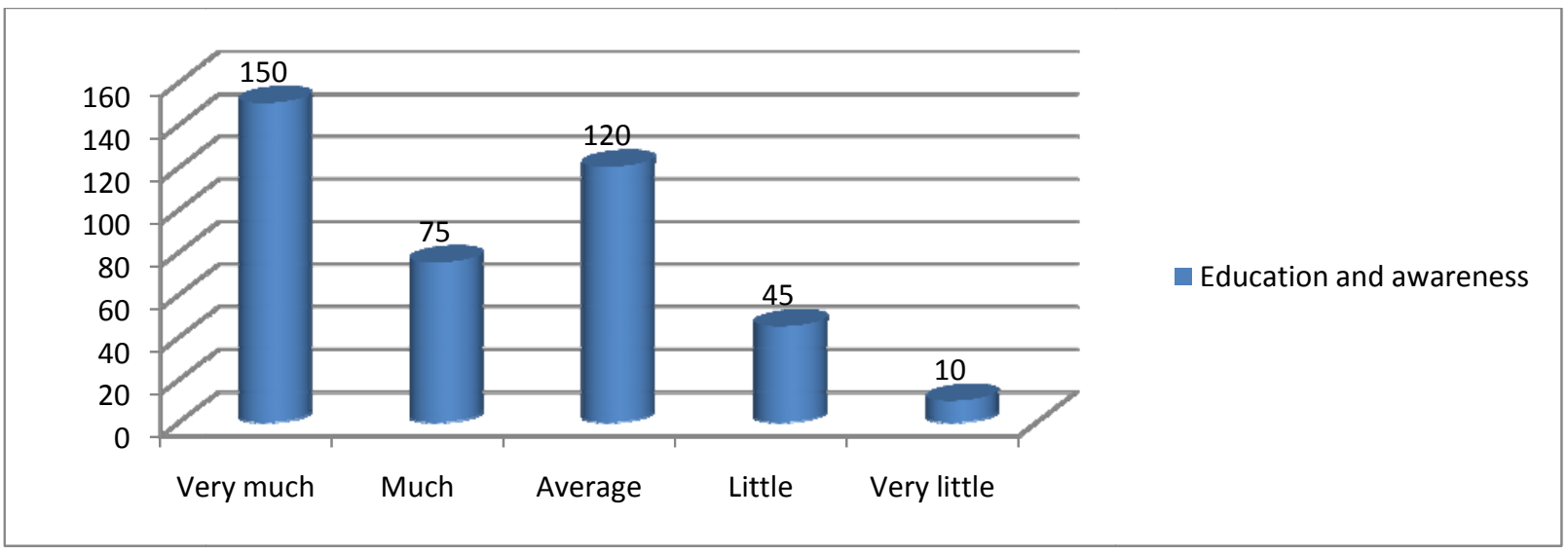

Fig. 4. The frequency of responses on the relevant importance of the effect of education on environment

As we can observe from the results of Fig. 4, 150 people strongly agreed that education and awareness play important role on having good environment, about 195 people were relatively positive on this issue and only 55 people did not believe that education and awareness could impact taking care of environment, significantly.

Finally, we have investigated the impact of traditional and religious believes on taking care of environment. Table 5 shows details of our test results of this hypothesis.

\section{Table 5}

Pearson correlation test results on the impact of traditional and religious believes on taking care of environment

\begin{tabular}{lcll}
\hline Variable & Correlation & P-value & Result \\
\hline Traditional and religious believes & 0.44 & 0.000 & Confirmed \\
\hline
\end{tabular}

Table 5 demonstrates the results of the responses for the last question of the survey. The P-value indicates that there is a meaningful relationship between educations effects and environmental issues and Pearson correlation indicates the relationship is indeed positive. Fig. 5 shows the frequency of the responses on this variable. 


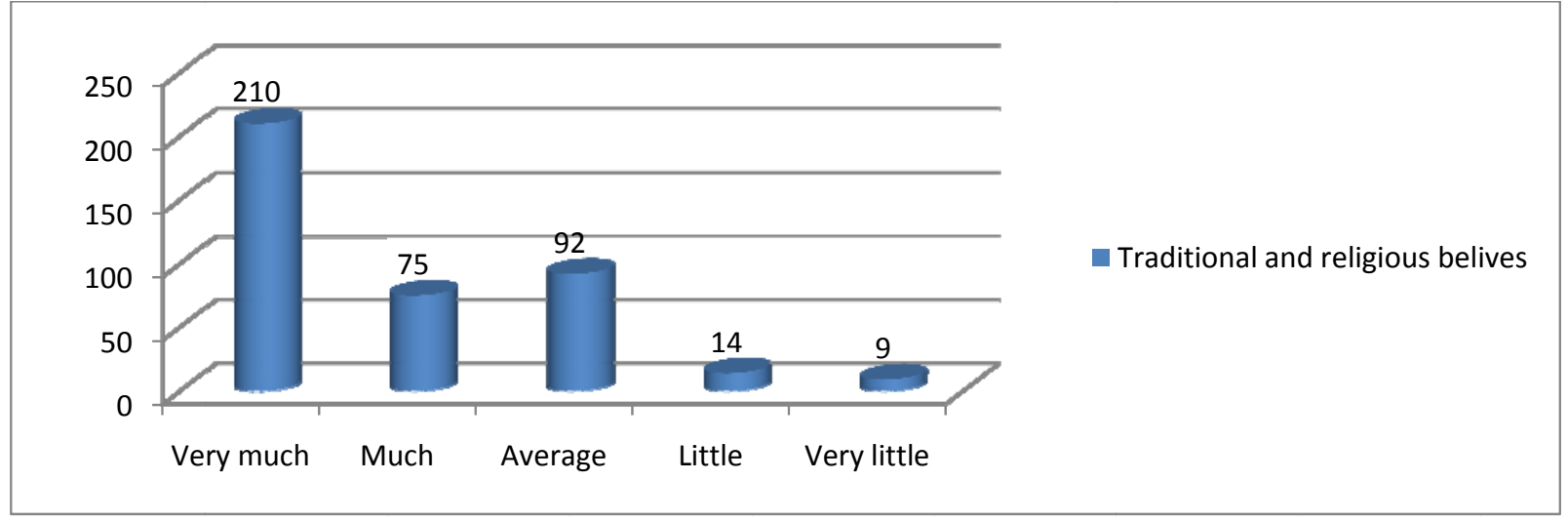

Fig. 5. The frequency of responses on the relevant importance of traditional and religious believes on environment

The results of this test show that over half of the people who participated in our survey believed that ethical issues could create good motivation among people to take care of environment.

\section{Conclusion}

In this paper, we have presented an empirical study to examine the effects of five different factors including responsibility, social ethics, normalization, education and awareness and religious and traditional believes on taking care of environment. The present study used a questionnaire and distributed among 400 people and, based on Pearson correlation test, examined the effect of these five variables on taking care of environment. The results indicate that while being responsible, social ethics, education and awareness have positive impact on taking care of environment; normalization policies have no meaningful influences on this issue. The results of our survey showed that religion and traditions have much stronger impact on having better environment.

\section{References}

Al-Khatib, J.A., Vitell, S. J., Rexeisen, R., \& Rawwas, M. (2005).Inter-country differences of consumer ethics in Arab countries. International Business Review, 14(4), 495-516.

Anderberg, S. (1998). Industrial metabolism and the linkages between economics, ethics and the environment. Ecological Economics, 24(2-3), 311-320

Brans, J.P. (2002). Ethics and decision. European Journal of Operational Research, 136(2), 340-352.

Ebadollahi Chanzanagh, H., \& Akbarnejad, M. (2011). The Meaning and Dimensions of Islamic Work Ethic: Initial Validation of A Multidimensional IWE in Iranian Society. Procedia - Social and Behavioral Sciences, 30, 916-924.

Fox, N., \& Ward, K. (2008). Health, ethics and environment: A qualitative study of vegetarian motivations. Appetite, 50(2-3), 422-429.

Kamla, R., Gallhofer, S., \& Haslam, J.(2006). Islam, nature and accounting: Islamic principles and the notion of accounting for the environment. Accounting Forum, 30(3), 245-265

Macbeth, J. (2005). Towards an ethics platform for tourism. Annals of Tourism Research, 32(4), 962984.

Sandler, R. (2012). Environmental Ethics. Encyclopedia of Applied Ethics, $2^{\text {nd }}$ ed., 105-113.

Schug, D.M. (2008). The institutional implications of environmental ethics for fishery management in the US exclusive economic zone. Marine Policy, 32(3), 514-521

Wareham, D.G., \& Elefsiniotis, P. (1996). Environmental ethics in engineering education: A missing fundamental. Water Science and Technology, 34(12), 197-203. 